\title{
Going Global: An International Survey of Lending and Borrowing Across Borders
}

\author{
TINA BAICH, IUPUI UNIVERSITY LIBRARY \\ HEATHER WELTIN, UNIVERSITY OF WISCONSIN, \\ MADISON
}

ILDS Conference, September 19, 2011 


\section{Overview}

- STARS:

$>$ Sharing and Transforming Access to Resources Section

- Purpose of RUSA STARS:

$>$ The purpose of the STARS International Interlibrary Loan Committee is to evaluate trends in international interlibrary loan (ILL) and resource sharing, to develop materials and resources for international ILL practitioners, and to promote international ILL resource sharing efforts.

- First Survey Initial Findings:

> Baich, T., Zou, T., Weltin H., Yang Z. (2009), "Lending and borrowing across borders: issues and challenges with international resource sharing", Reference and User Services Quarterly, Vol. 49, No. 1, pp. 5463. 


\section{Demographics: Total Requests by Continent}

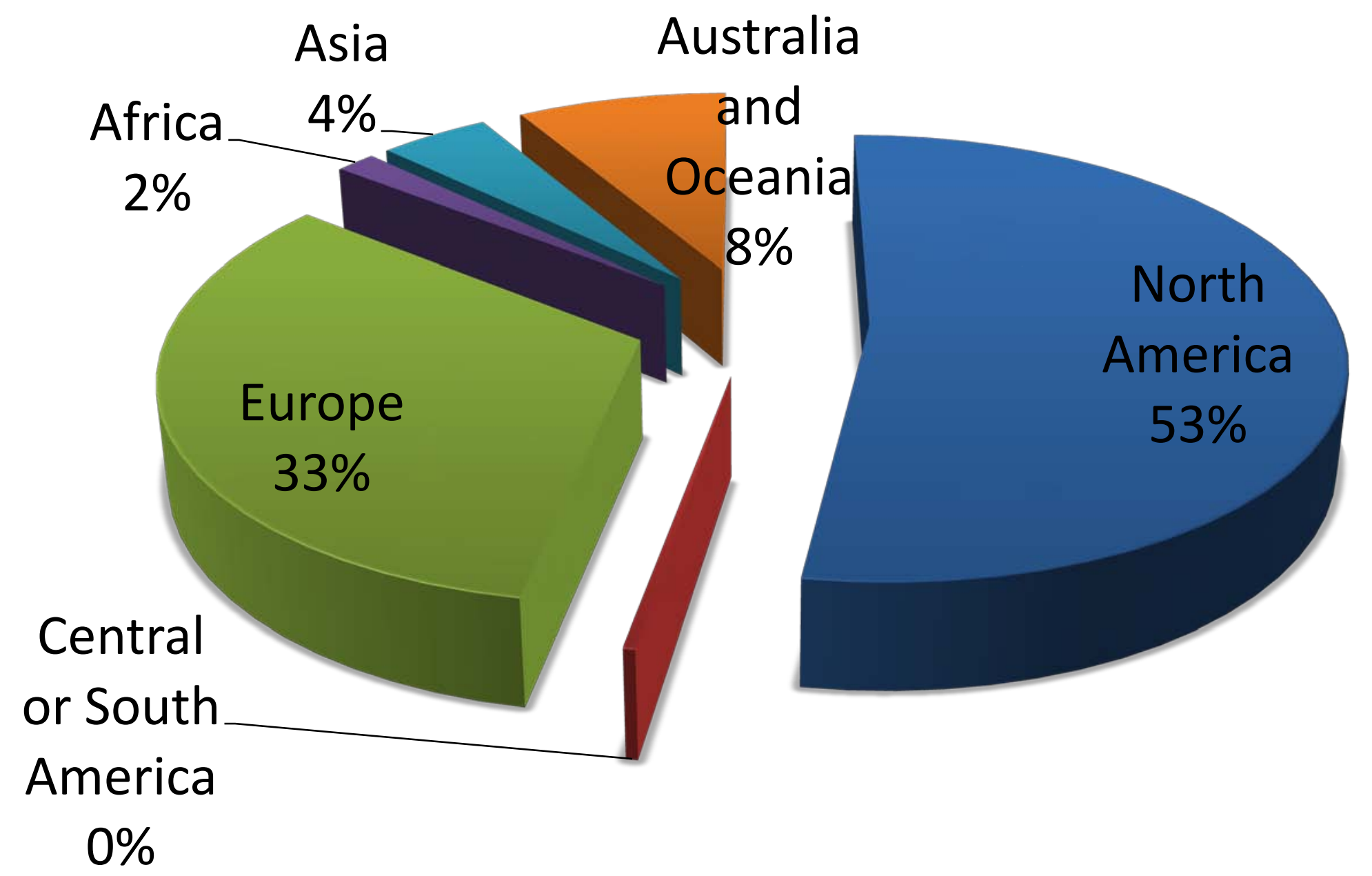




\section{Demographics: Volume of International Requests}

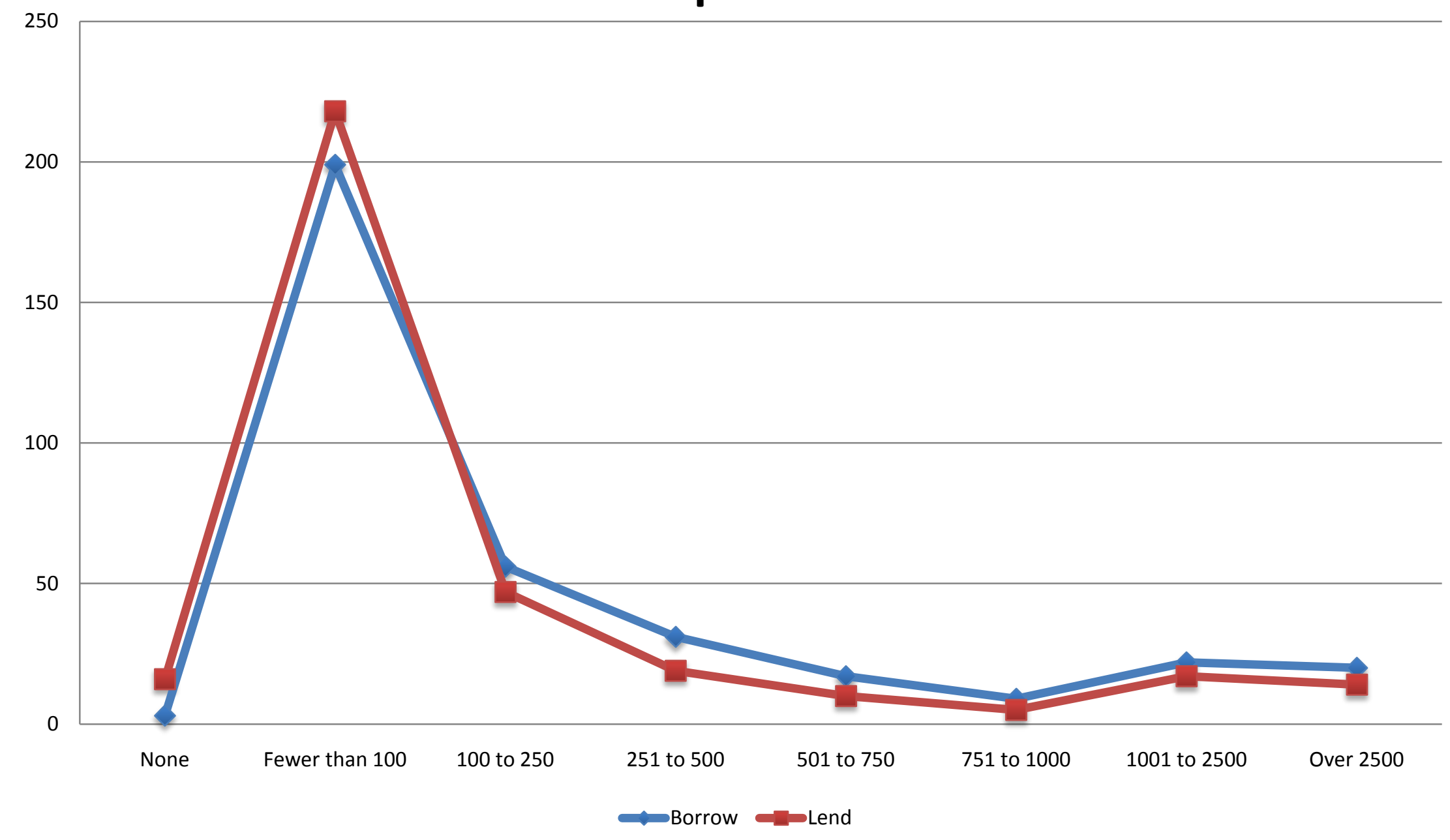


Borrowing 


\section{Types of Materials Requested Internationally}

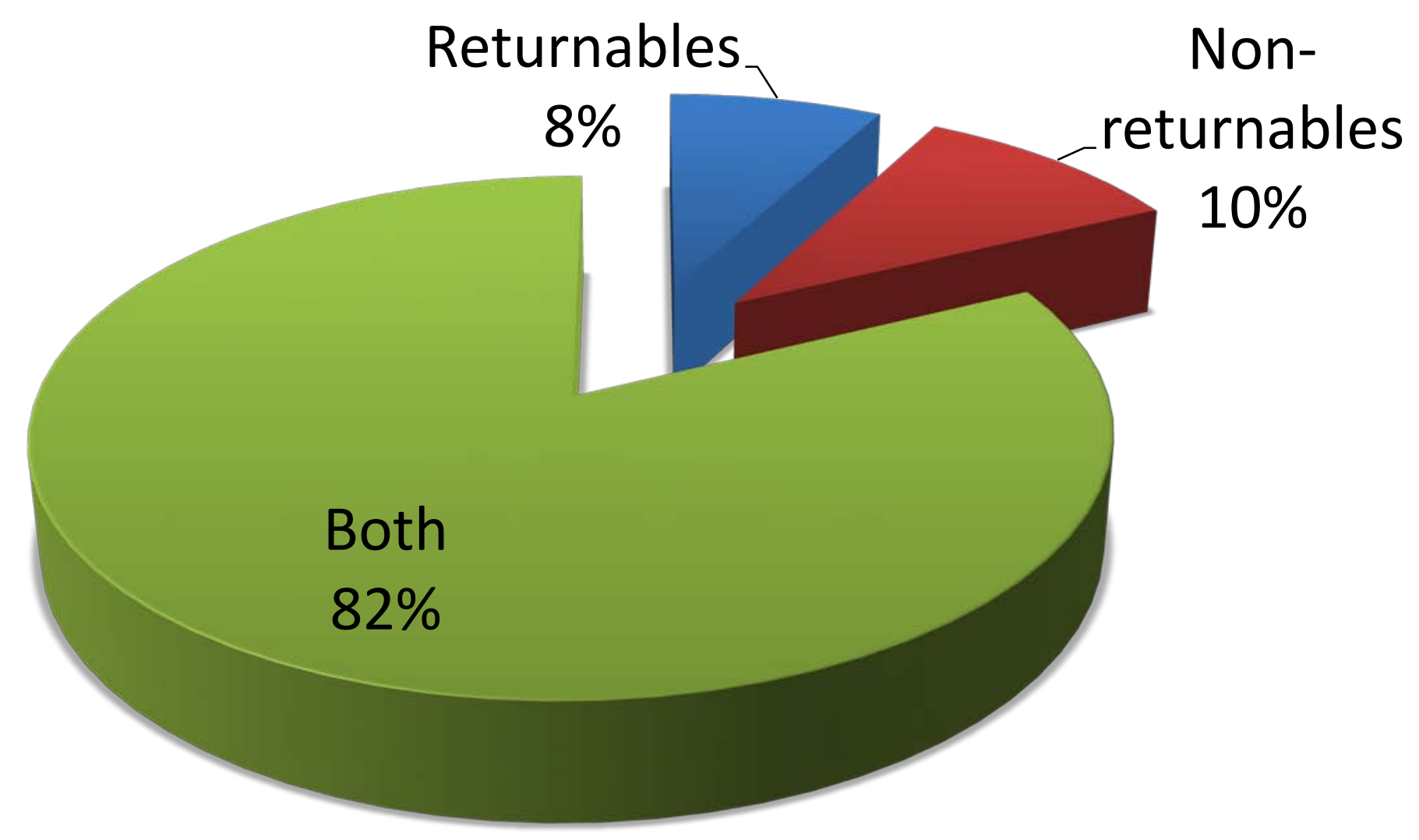




\section{Continents from Which Libraries Will Borrow}

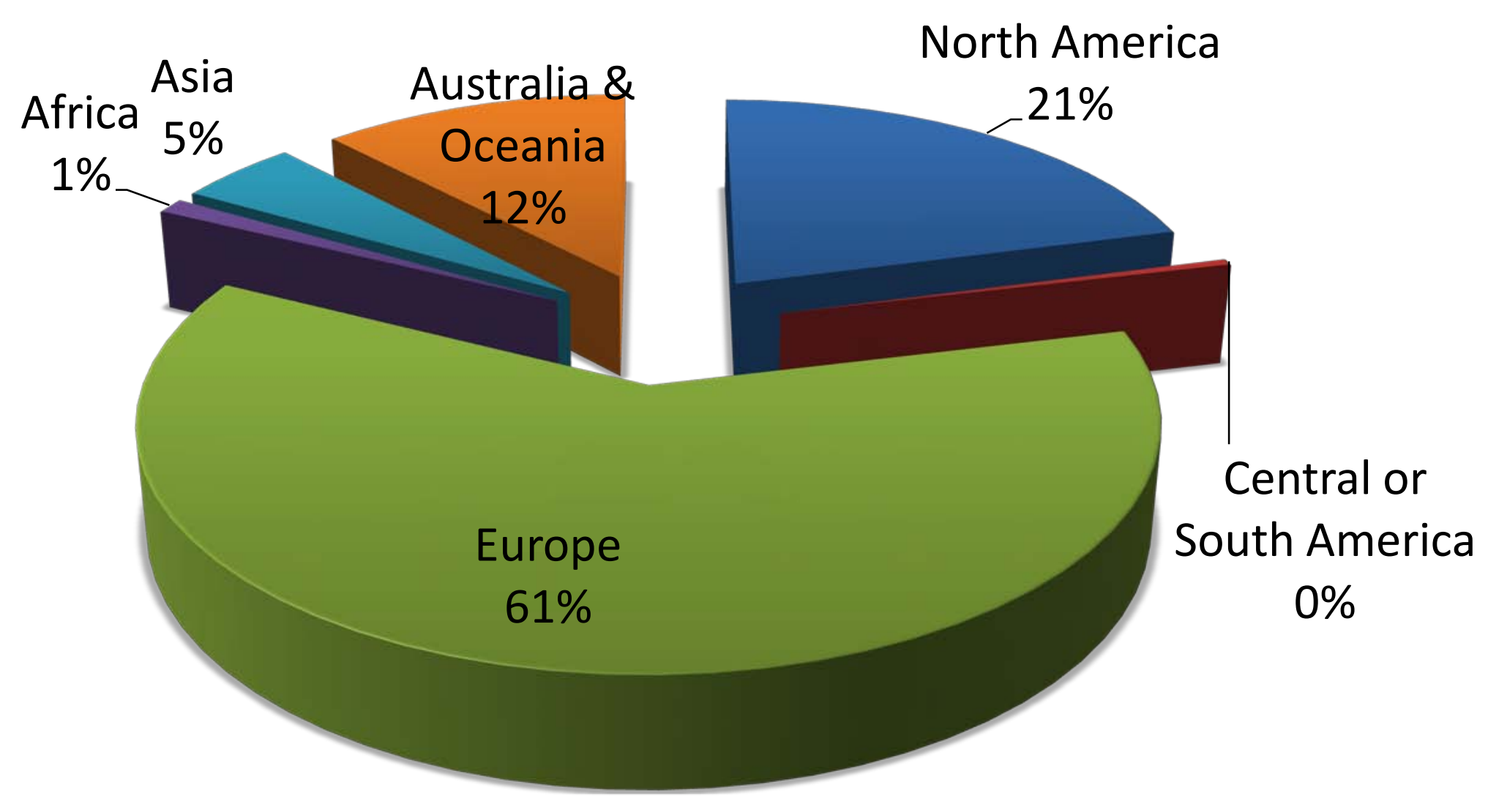




\section{Hard to Obtain Materials}

Copies of rare or older materials Local dissertations $\mathrm{CD} /$ Audio media Electronic books Video/Film media

Serials (bound volumes/issues)

Microforms

Music scores

Other

Books

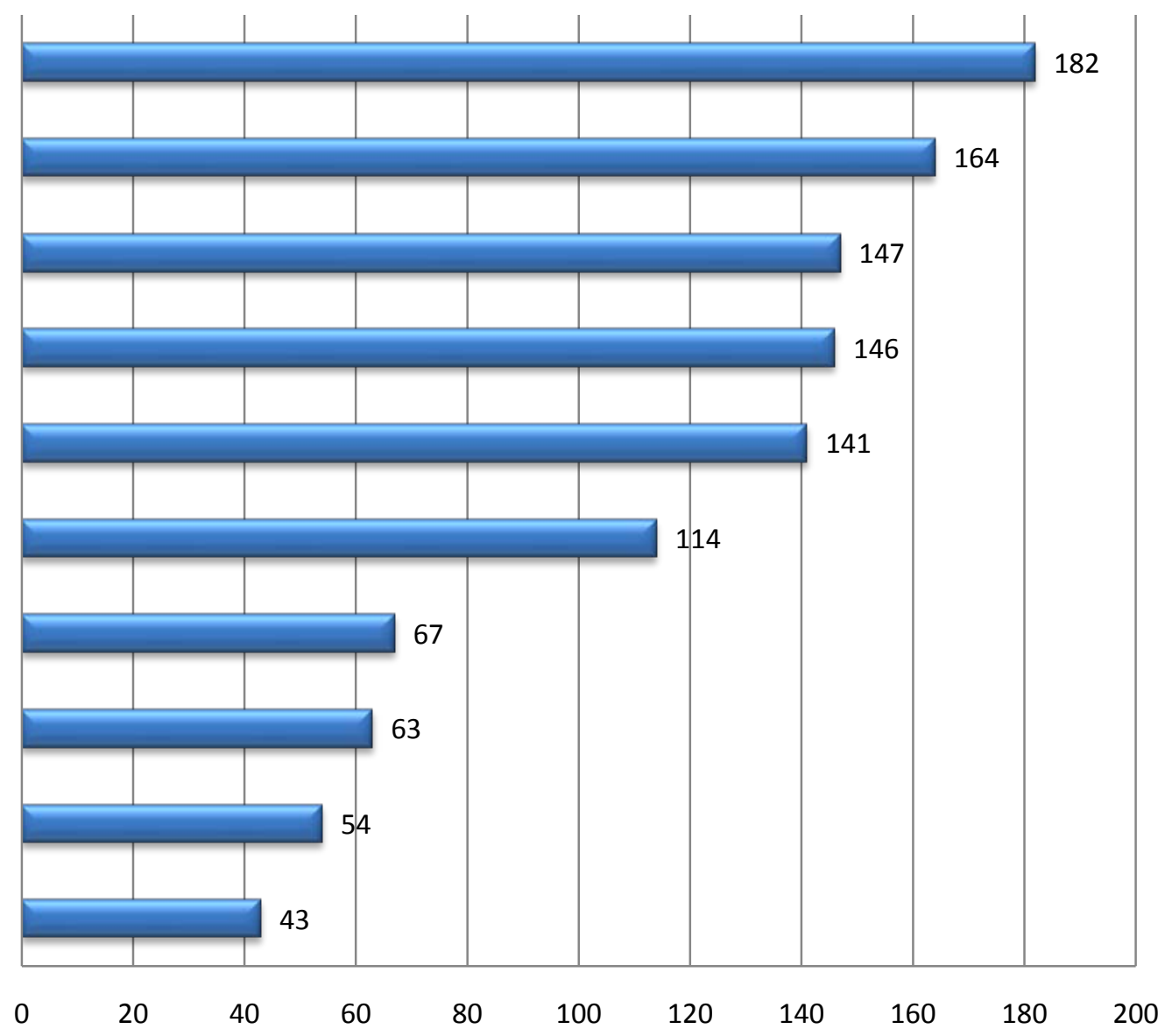




\section{Lending}




\section{Types of Materials Lent Internationally}

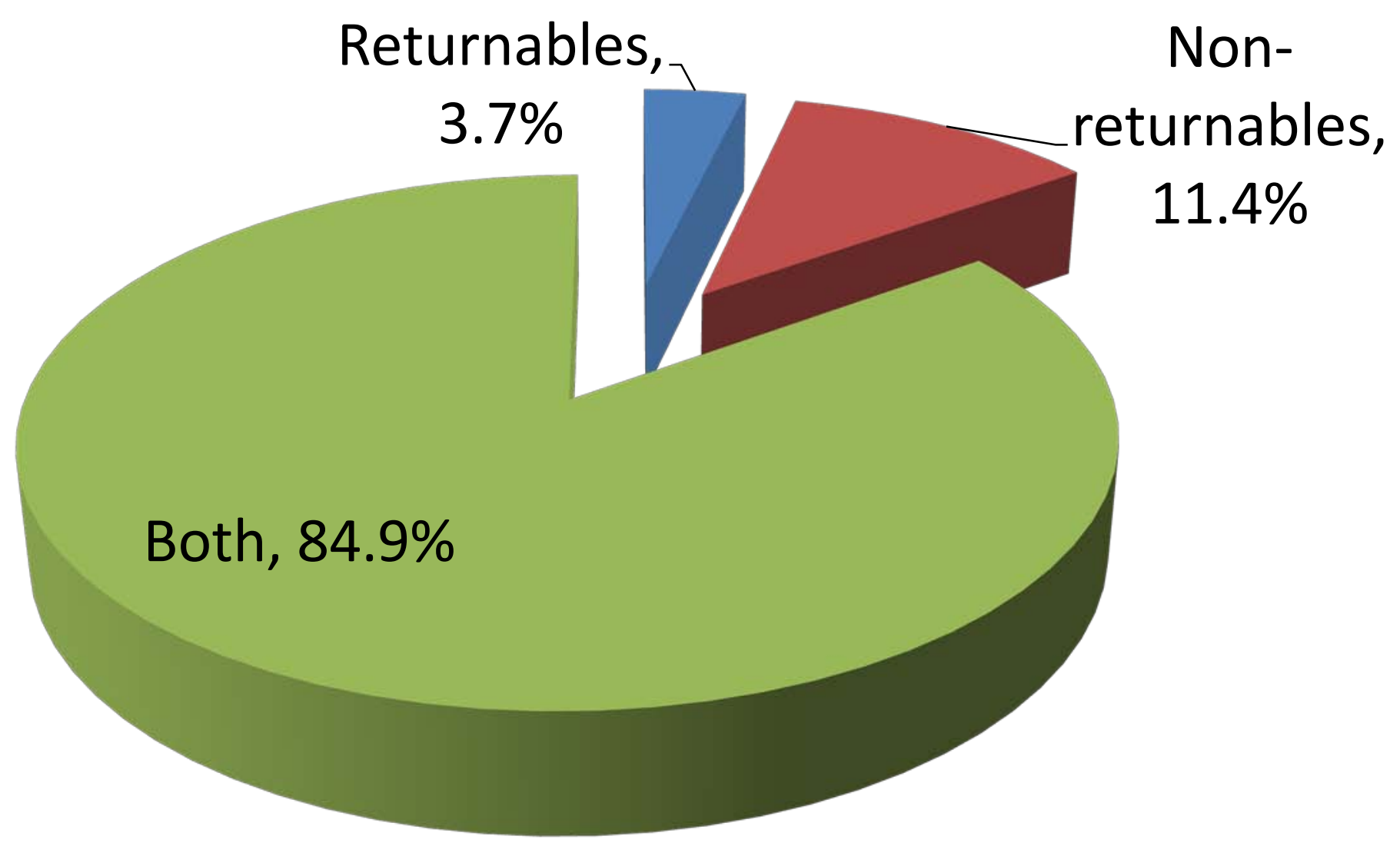




\section{Countries to Which Libraries Will Lend}

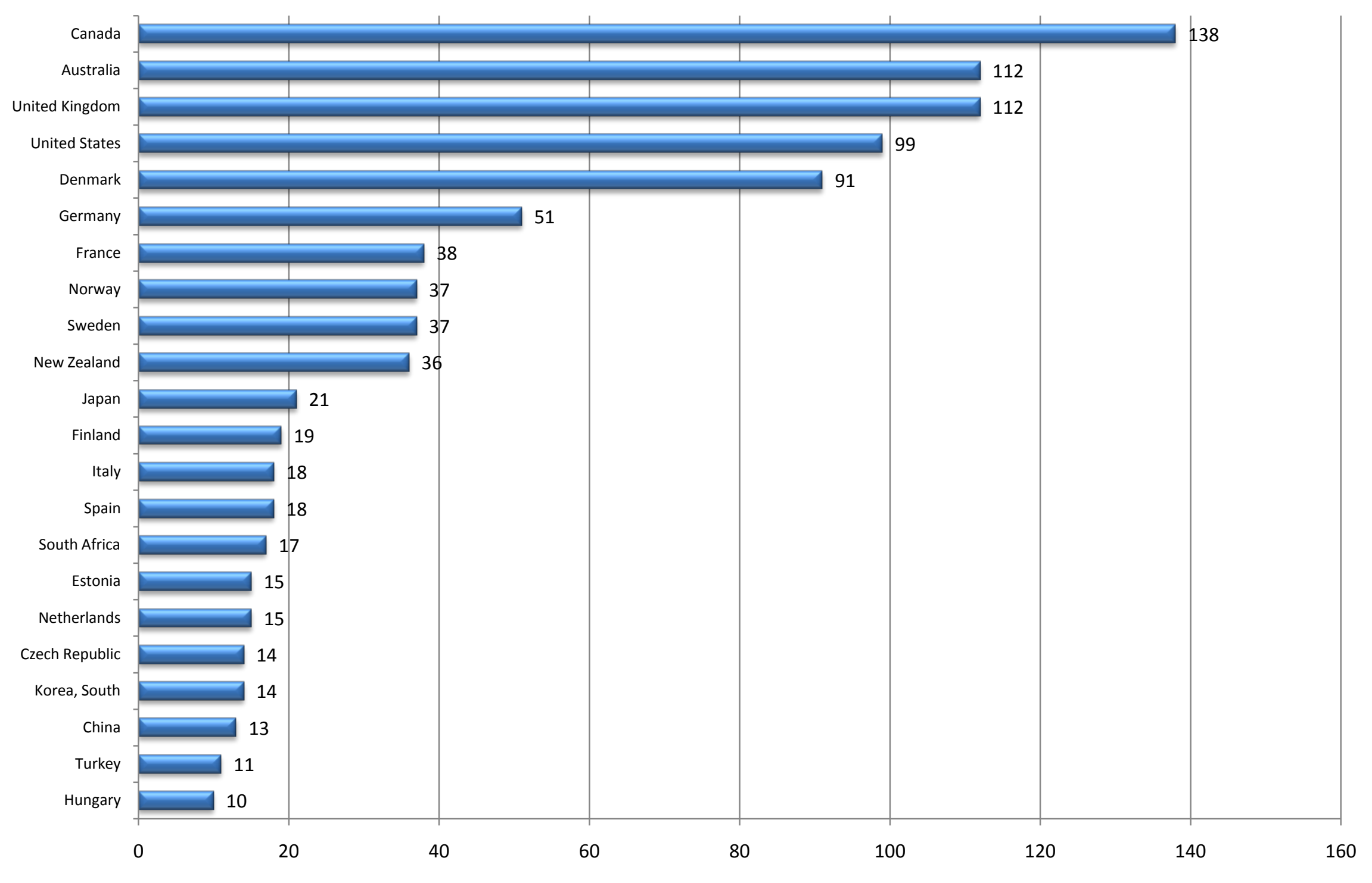




\section{Countries to Which Libraries Will Not Lend}

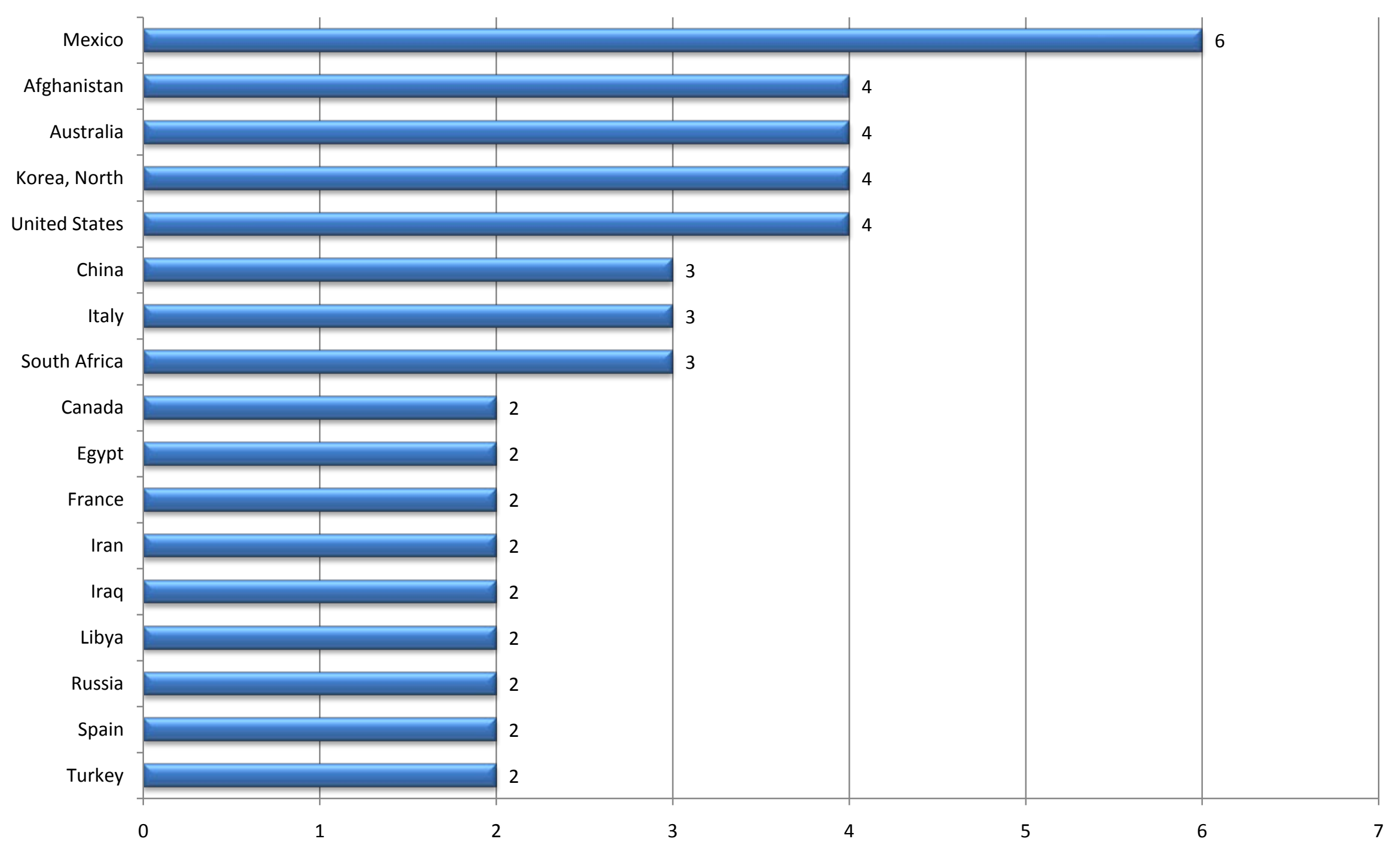




\section{Comparison}

\section{7 survey of US libraries}

- Over $50 \%$ have annual volume of less than 5,000

- $94 \%$ borrow and lend internationally

- Canada, Australia, UK among top countries from which libraries borrow and to which libraries will lend

- Videos/Films, Books more than 100 years old, \& Dissertations identified as most difficult to borrow
2011 survey of international libraries

- Over $50 \%$ have annual volume of less than 5,000

- $87.3 \%$ borrow internationally

- $86.9 \%$ lend internationally

- Canada, Australia, UK among top countries from which libraries borrow and to which libraries will lend

- Copies of rare or older materials, Dissertations, \& $\mathrm{CD} /$ Audio media identified as most difficult to borrow 


\section{Summary}

- Level of international ILL activity

$>51 \%$ reported an increase of at least $10 \%$

$>$ Visibility of collections

- Online lending policies

$>$ Only $35.7 \%$ make available on library website

- Next step

$>$ Full analysis of survey results and release of executive report 


\title{
Questions?
}

\author{
Tina Baich \\ cbaich@iupui.edu \\ Heather Weltin
}

hweltin@library.wisc.edu 